\title{
The pulsating nature of bubble boiling of subcooled water flow during cooling of a metal heater
}

\author{
Levin A.A.
}

Novosibirsk State University, 2, Pirogova street, Novosibirsk, Russia

Melentiev Energy Systems Institute, 130, Lermontova street, Irkutsk, Russia

\begin{abstract}
This paper presents the results of an experimental study of the subcooled water flow boiling on the surface of a metal rod $12 \mathrm{~mm}$ in diameter. As a result of the rapid heat release that occurs when an electric current is pulsed through a metal heater, the latter reaches certain temperature levels above the saturation temperature of water at the corresponding pressure $(p=0.17 \mathrm{MPa})$. In a system formed by a cold liquid and a heated solid body, the process of intense heat exchange begins, the cooling rate of the metal in which reaches its maximum when the nucleate boiling is realized. Interest in such scenarios is remaining high and is caused by the need for quantitative prediction of the characteristics of nucleate boiling and the existence boundaries of this boiling mode. As well-known, nucleate boiling is limited from above by the onset of film boiling and from below by the required surface temperature for which a significant number of nucleation centers are activated. The pressure waves arising during film boiling have a significant amplitude, as a result of which special conditions of interphase interactions may occur. The results of the study showed that self-oscillating pressure pulsations may occur which is associated with the nucleate boiling in an annular channel.
\end{abstract}

\section{Introduction}

The usage of liquid cooling in heat exchange devices with an intentional (or resulting from an accident) phase transition requires the ability to predict characteristics of the gas phase. This area of research includes both the determination of the characteristics of bubbles or vapor films and the determination of the dynamics of pressure, vapor content and other critical parameters of the equipment operation. Despite significant efforts made to solve these problems, most of the operating parameters can be determined only on the basis of empirical data. This happens due to the complexity of the processes under consideration, as well as a large number of phenomena of different scales accompanying the processes of interphase interactions. In this regard, due to the large number of combinations of operating conditions (pressure, fluid properties, surface characteristics, etc.), experimental studies of heat transfer between a hot solid surface and a subcooled fluid flow are important for real-life problems.

The usage of liquid cooling in heat exchange devices with pressure pulsations creates experimental conditions with an oscillating saturation temperature while the wall temperature gradually a smooth changes. This is especially important when testing existing approaches to determining the characteristics of nucleate boiling, since the overwhelming part of the experimental database was obtained with constant pressures, heat fluxes, etc. Another feature of the problem under consideration is the relationship between nucleate boiling and the development of hydrodynamic instability in the annular channel. Previously, we showed that a super-intense type of heat transfer between a heater with a temperature above the Leidenfrost point and a subcooled ethanol flow is possible [1-2]. The key condition for the implementation of such heat transfer was the emergence of self-sustained pressure pulsations. This paper presents the results of the study of cooling a metal tube by a flow of subcooled water to the saturation temperature.

\section{Experimental setup}

The scheme of the experimental unit that was used in the present study consists of the transparent test section with a heater, a pump, a condenser, a degasation tank, and devices that automatically control experimental conditions (pressure, flow, and temperature). A preheated metal rod (diameter $12 \mathrm{~mm}$, length $100 \mathrm{~mm}$ ) is cooled by a flow of subcooled water to the saturation temperature. To achieve the required surface temperature $\left(T_{\mathrm{w}}=200{ }^{\circ} \mathrm{C}\right)$, an electric current was passed through the heater. Surface roughness was measured using a TR200 stylus. The average surface roughness $\left(R_{\mathrm{a}}\right)$ was about $0.9 \mathrm{~lm}$, and the maximum roughness $\left(R_{\max }\right)$ was $4 \mathrm{~lm}$. The test section was equipped with the temperature, voltage and pressure measuring probes. The inlet water subcooling was in the range from 51 to $78{ }^{\circ} \mathrm{C}$. The heating power was generated by conducting three-phase rectified electric current through the heater with the pulse duration of 150 ms. To provide degasification, we boiled water circulating in the experimental unit for several hours. Gases were eliminated through degassing tank which 
was connected to the atmosphere. After that the degassing tank was blocked out by closing the switching

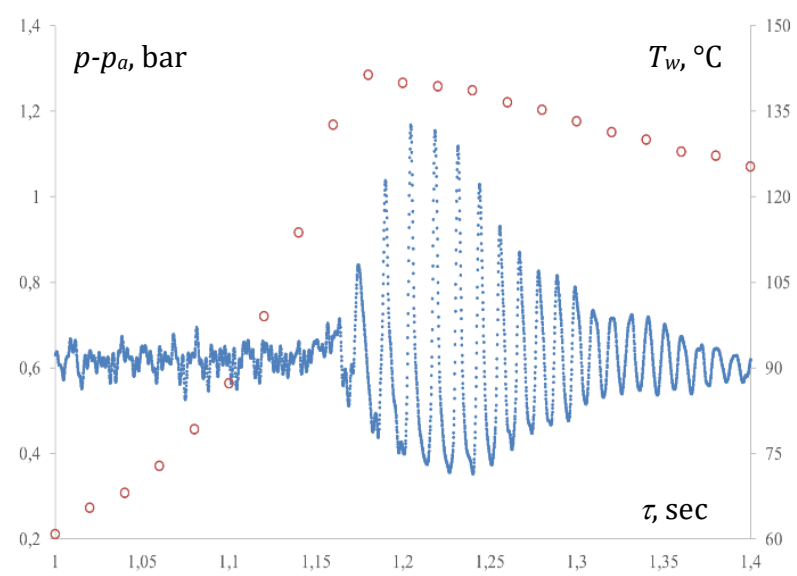

valves. The pressure in the test section was $0.15 \mathrm{MPa}$.

Fig. 1. Pressure oscillations and temperature changes during the process of the energy released at heater and its cooling by subcooled water flow. $T_{0}=60^{\circ} \mathrm{C}, p_{0}=0.15 \mathrm{MPa}$.

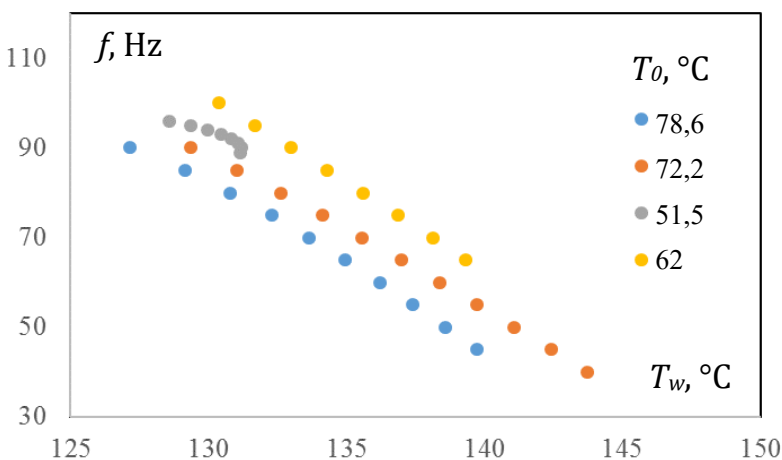

Fig. 2. Pressure pulsation frequency dependence on surface temperature.

An intense heat transfer process begins between a subcooled liquid and a solid, the rate of which reaches its highest level if there are of bubbles on the surface. Interest in such situations is obviously caused by the need to predict both the characteristics of nucleate boiling and the limits of existence of self-oscillating pressure fluctuations arising as a result of the formation and degradation of the vapor phase (Fig.1).

\section{RESULTS AND DISCUSSION}

Figure 1 reveals the self-oscillating nature of pressure pulsations, the amplitude of which reaches 0.93 bar in the absence of electric energy release. The selfsustaining nature of this oscillatory process is caused by the coincidence of the natural frequency of the vaporliquid column inside the working section and the total frequency of growth of the bubble conglomerate on the surface of the heater. At the stage of increasing pressure, the saturation temperature increases, and the corresponding surface overheat decreases below the limiting value, below which the appearance of new bubbles stops. This leads to the bubbles collapse predominance, as a result of which the pressure begins to decrease, returning the heater - liquid system to its original state. The cooling rate of the heater metal is rather low, which allows the self-oscillating process to carry on for quite a long time.
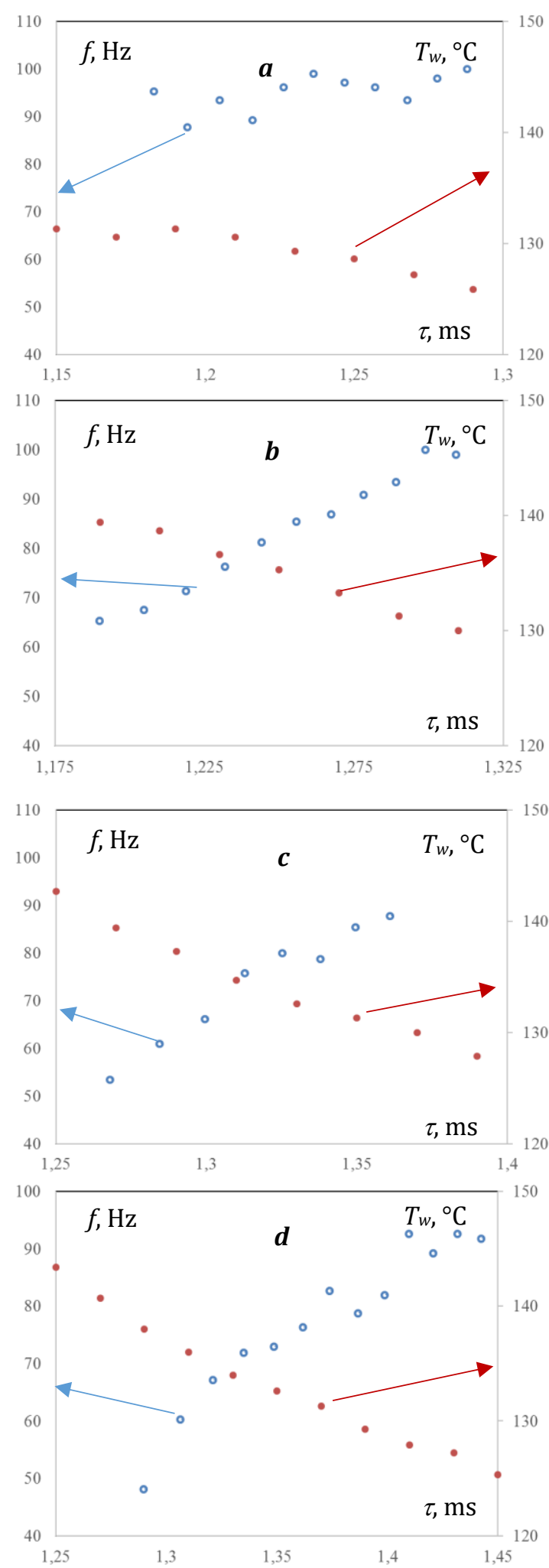

Fig. 3. Dynamic of the surface temperature and the pressure oscillation frequency during the cooling process of metal rod. Experimental conditions: $p_{0}=0,15 \mathrm{MPa} ; w_{0}=0,58 \mathrm{~m} / \mathrm{s}$. Initial temperature of the water: a) $T_{0}=51,7^{\circ} \mathrm{C}$; b) $T_{0}=62^{\circ} \mathrm{C}$; c) $T_{0}=72,2^{\circ} \mathrm{C}$; d) $T_{0}=78,6^{\circ} \mathrm{C}$. 


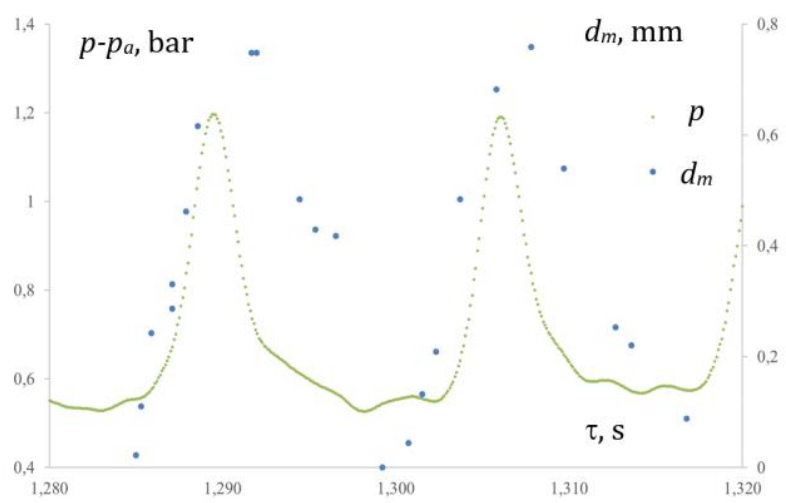

Fig 4. Dynamic of the pressure and maximum bubble diameter during the self-oscillation pulsation.

Figures 2 and 3 compares the values of the frequency of pressure pulsations in the channel with the surface temperature during the cooling of the metal surface. It is easy to see that the pulsation frequency increases with decreasing surface temperature for any initial value of the liquid temperature. With a decrease in the surface temperature, the sizes of the formed bubbles decrease, and, as a consequence, the volume of the vapor phase in the channel, as well as the period of its growth, also decrease.

The largest pressure drop in the experimental data with different initial liquid temperature levels was observed with minimum level of the subcooling. This is due to the large amount of the vapor mass formed during the boiling of the liquid with the highest temperature, because the diameter of individual bubbles becomes larger. The life span of the bubbles also increases and the nucleation frequency decreases. The equation based on the heat balance $[5,6]$ predicted the present experimental data of maximum bubble diameter (Fig.4) with an average error of $35 \%$ :

$$
D_{m}=1,21 A B^{-0,5}
$$

where, $A$ and $B$ are overheating and subcooling factors respectively, calculated by the method presented at [6].

\section{Conclusions}

We presented the results of an experimental study of unsteady heat transfer for a metal heater cooled by a subcooled water flow. We showed that self-oscillating pressure pulsations may occur as a result of a combination of the hydrodynamic properties of the working section and the dynamic characteristics of the vapor phase. The key characteristics of nucleate boiling were determined and compared with known predictive models for the bubble diameter.

This research was performed at the Melentiev Energy Systems Institute SB RAS using the equipment of the HighTemperature Circuit Multi-Access Research Center and was funded by the Russian Science Foundation, project no. 19-1900122.

\section{References}

1. Levin, A. A., Tairov, E. A., \& Spiryaev, V. A., Selfexcited pressure pulsations in ethanol under heater subcooling. Thermophysics and Aeromechanics, 24, 1 (2017).

2. Aktershev, S. P., Levin, A. A., Mesentsev, I. V., \& Mesentseva, N. N. Self-oscillatory regime of boiling of a highly subcooled liquid in a flowpassage annular duct. Thermophysics and Aeromechanics, 25, 6 (2018).

3. K. Okuyama, S. Mori, K. Sawa, and Y. Iida, Dynamics of boiling succeeding spontaneous nucleation on a rapidly heated small surface, Int. J. Heat Mass Transfer, 49 (2006).

4. Z. Zhao, S. Glod, and D. Poulikakos. Pressure and power generation during explosive vaporization on a thin-film microheater, Int. J. Heat Mass Transfer, 43 (2000).

5. Levin, A. A., \& Khan, P. V. Experimental observation of the maximum bubble diameter in non-stationary temperature field of subcooled boiling water flow. International Journal of Heat and Mass Transfer, 124, (2008).

6. N.H. Hoang, C.H. Song, I.C. Chu, D.J. Euh,Abubbledynamics-basedmodel for wall heat flux partitioning during nucleate flow boiling, Int. J. Heat Mass Transf. 112 (2017). 